\title{
Prevalence of Dyskinesia and OFF by 30-Minute Intervals Through the Day and Assessment of Daily Episodes of Dyskinesia and OFF: Novel Analyses of Diary Data from Gocovri Pivotal Trials
}

\author{
Robert A. Hauser ${ }^{\mathrm{a}, *}$, Daniel E. Kremens ${ }^{\mathrm{b}}$, Lawrence W. Elmer ${ }^{\mathrm{c}}$, David L. Kreitzman ${ }^{\mathrm{d}}$, \\ Ryan R. Walsh ${ }^{\mathrm{e}}$, Reed Johnson ${ }^{\mathrm{f}}$, Robert Howard ${ }^{\mathrm{g}}$, Jack T. Nguyen ${ }^{\mathrm{f}}$ and Rajiv Patni ${ }^{\mathrm{f}}$

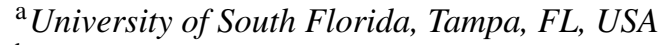 \\ ${ }^{\mathrm{b}}$ Thomas Jefferson University, Philadelphia, PA, USA \\ ${ }^{\mathrm{c}}$ University of Toledo College of Medicine, Toledo, OH, USA \\ 'Parkinson's Disease and Movement Disorders Center of Long Island, Commack, NY, USA \\ ${ }^{\mathrm{e}}$ Muhammad Ali Parkinson Center at Barrow Neurological Institute, Phoenix, AZ, USA \\ ${ }^{\mathrm{f}}$ Adamas Pharmaceuticals, Inc., Emeryville, CA, USA

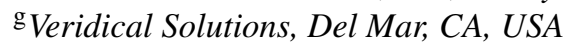

Accepted 10 March 2019

\begin{abstract}
.
Background: Parkinson's disease (PD) patients using levodopa commonly develop dyskinesia and OFF episodes that reduce quality of life.

Objective: Evaluate prevalence of troublesome dyskinesia and OFF through the day, assessed by 30-minute intervals, as well as the mean number and duration of troublesome dyskinesia and OFF episodes, transitions between PD states, and effects of Gocovri $^{\circledR}$ (amantadine) extended release capsules on these episodes.

Methods: Evaluate diary data from pooled Gocovri phase 3, placebo-controlled trials—analyzed for 17 hours following wake-up-at baseline and week 12.

Results: Diaries were evaluable for 162 patients. At baseline, $67 \%$ of patients woke up OFF, with prevalence decreasing to $13 \%$ at 2 hours and then remaining relatively steady at $\sim 12 \%$ (range, 6-17\%) across half-hour intervals thereafter. Troublesome dyskinesia prevalence rose steadily from $5 \%$ to $24 \%$ over the first 2 hours, then fluctuated between $20 \%$ and $44 \%$ through the rest of the waking day. At baseline, patients experienced a mean of 3.0 daily episodes of troublesome dyskinesia (average duration 2.0 hours each), and 2.2 daily episodes of OFF (average duration 1.1 hour each). At week 12, Gocovri-treated patients showed greater reductions than placebo in troublesome dyskinesia and OFF episodes per day (treatment difference: -1.0 episodes and -0.4 episodes, respectively) and average episode duration (treatment difference: -0.6 hours and -0.3 hours, respectively). Mean duration of individual episodes of ON without troublesome dyskinesia (Good ON) increased by 5.0 hours for Gocovri, compared with 2.0 hours for placebo. Patients taking Gocovri experienced 2.2 fewer transitions between states than patients taking placebo.
\end{abstract}

\footnotetext{
${ }^{*}$ Correspondence to: Robert A. Hauser, MD, MBA, Department of Neurology, Parkinson's Disease and Movement Disorders Center, Parkinson Foundation Center of Excellence, University
}

of South Florida, 4001 East Fletcher Avenue, Tampa, FL 33596, USA. Tel.: +1 813396 0768; Fax: +1 813905 9829; E-mail: rhauser@health.usf.edu. 
Conclusions: Troublesome dyskinesia and OFF occurred in the morning and throughout the waking day. Gocovri-treated patients experienced fewer, shorter episodes of both troublesome dyskinesia and OFF, thereby increasing the duration of continuous Good ON episodes and reducing the frequency of transitions between motor states.

Keywords: Amantadine, delayed-action preparations, double-blind method, dyskinesias, OFF, episodes, humans, levodopa, Parkinson disease, transitions, treatment

\section{INTRODUCTION}

Patients on chronic levodopa therapy for Parkinson's disease (PD) commonly develop OFF and dyskinesia as PD progresses, often with significant impact on daily life [1-5]. Such patients are typically faced with a medication management trade-off, in which adjusting the dosage or dosing frequency of levodopa or adjunctive drugs may reduce OFF time but worsen dyskinesia, or may reduce dyskinesia but result in increased OFF time [6-8]. To our knowledge, there have to date been no investigations specifically evaluating the temporal pattern of OFF and dyskinesia through the day. An understanding of these timing patterns, might offer new insights into the expression of motor complications, thereby improving PD symptom management and associated quality of life (QOL) [9]. In addition, prior studies of adjunctive medications in PD have focused on total daily OFF time and total daily time with troublesome dyskinesia, and there has been little or no information provided regarding effects on the number and duration of individual episodes of these states.

Gocovri $^{\circledR}$ (amantadine) extended release capsules (Adamas Pharmaceuticals, Inc.) is an orally administered high-dose, extended-release formulation of amantadine approved for the treatment of dyskinesia in patients with PD taking levodopa-based therapy. Amantadine acts as an uncompetitive antagonist of the N-methyl-D-aspartate glutamate receptor, which is thought to be overstimulated in the striatum of dyskinetic PD patients $[10,11]$. Gocovri is designed to be dosed once-daily at bedtime. Delayed drug release and slow rise in plasma concentrations provide high amantadine concentrations in the morning and throughout the waking day with lower evening exposure [12]. In each of 2 published, double-blind, placebo-controlled phase 3 trials (EASE LID [13] and EASE LID 3 [14]), patients with dyskinesia completed PD home diaries [15] at baseline (before exposure to study drug) and at treatment time points, including week 12 (primary endpoint). In both trials, Gocovri provided a significant reduction in dyskinesia as assessed using the Unified Dyskinesia Rating Scale (UDysRS) [16] as well as a significant reduction in total daily OFF time and troublesome dyskinesia (as assessed by PD home diaries), resulting in a mean increase in total daily $\mathrm{ON}$ time without troublesome dyskinesia (also known as Good ON time) $[13,14,16]$.

Here we have applied novel analyses to the pooled diary data from these pivotal trials to: 1) map baseline population prevalence of dyskinesia and OFF by 30 -minute intervals through the day; 2) assess the individual mean number and duration of daily episodes of troublesome dyskinesia and OFF, as well as the number of daily transitions between PD states; and 3) evaluate the effects of Gocovri on these PD patterns.

\section{METHODS}

\section{Study designs and participants}

The EASE LID trial [13] (ClinicalTrials.gov identifier: NCT02136914) was conducted at 44 North American sites between May 2014 and July 2015, and the EASE LID 3 trial [14] (NCT02274766) at 39 sites in the US and Western Europe between October 2014 and December 2015. All patients were required to be experiencing at least one hour/day (2 half-hour intervals) of ON time with troublesome dyskinesia between 9 am and $4 \mathrm{pm}$, on the two days preceding treatment initiation, as documented by entries in PD home diaries [15]. The dyskinesia was required to be causing at least mild functional impairment, as documented at screening and baseline by a score $\geq 2$ on item 4.2 of the Movement Disorder Society-Unified Parkinson's Disease Rating Scale (MDS-UPDRS) [17]. Enrolled patients were randomized in a $1: 1$ ratio to double-blind Gocovri or placebo once daily at bedtime. Gocovri was initiated at $137 \mathrm{mg} /$ day (equivalent to $170 \mathrm{mg}$ of amantadine $\mathrm{HCl}$ ) for the first week and titrated to $274 \mathrm{mg} /$ day (equivalent to $340 \mathrm{mg}$ of amantadine $\mathrm{HCl}$ ) thereafter.

\section{Efficacy measures and analyses}

In both trials, the primary outcome was change from baseline in UDysRS total score, as assessed at 
week 12. In each trial, this outcome was analyzed in the modified intent-to-treat (mITT) population, comprising all randomized patients who were exposed to study drug, and underwent at least 1 post-baseline UDysRS assessment. The present analyses include all patients with evaluable PD home-diary data for a 2-day period at baseline and at week 12, as defined in each trial's Statistical Analysis Plan (see Supplementary Material).

In PD home diaries, patients categorize their predominant motor state during each half-hour interval of the 24-hour day as 1 of 5 categories: ON with no dyskinesia, ON with non-troublesome dyskinesia, ON with troublesome dyskinesia, OFF, or asleep [15]. For the present analyses, we combined the first 2 categories (ON with no dyskinesia and $\mathrm{ON}$ with non-troublesome dyskinesia) into a single category of ON without troublesome dyskinesia, or "Good ON." At baseline, and independently at week 12, each patient's wake-up time was defined as the start of the first of 4 consecutive half-hour intervals not reported as asleep on the second day of diary-keeping, beginning at or after 3 am (as rated in the diary entry for $3: 30 \mathrm{am}$ ). Because each 24-hour diary started at 6 am, when some patients were already awake, the second day's data were utilized for all analyses. The 17-hour time span following wake-up time could then be plotted by predominant status during each halfhour interval, for descriptive assessment at baseline and at week 12, across these visits, and across treatment groups. An "episode" was defined as time spent in a PD-diary state (ON without troublesome dyskinesia, ON with troublesome dyskinesia, or OFF) before transitioning to any other state, thereby beginning a new episode. "Asleep" during the day was not considered a transition, but its time was not reallocated to other episodes. Time periods during which sleep interrupted a single category of PD state were counted as two episodes of that state. Descriptive statistics were compiled for total number of transitions between each motor state, as well as the number of each type of episode, their average duration, duration of the first such episode, and for week 12 data, the proportions of patients with no dyskinesia or OFF episodes (a 17-hour waking day free of ON time with troublesome dyskinesia, free of OFF time, or free of both).

For calculation of the treatment difference between Gocovri vs. placebo at week 12, a Mixed-Effect Model Repeated Measure (MMRM) analysis was used with change from baseline as the dependent variable and baseline value as a covariate. The model, which was generated in SAS version 9.4 (SAS Institute Inc., Cary, North Carolina), included categorical effects for treatment group, study, and visit (Weeks 2,8 , and 12), and the interaction between treatment group and visit. The treatment differences between Gocovri and placebo for the mean changes from baseline through week 12 in the number of transitions per day, total ON time with troublesome dyskinesia, OFF time, and ON time without troublesome dyskinesia were calculated using a Wilcoxon two-sample test at the 0.05 significance level.

\section{Ethical conduct}

Each study was conducted in accordance with the Declaration of Helsinki and with Good Clinical Practice guidelines. Before the start of each study, each study site received approval from an institutional review board, research ethics board, or independent ethics committee; before any study procedures, written informed consent was obtained from each patient.

\section{RESULTS}

\section{Study participants}

Across the EASE LID [13] and EASE LID 3 [14] studies, the pooled mITT population comprised 196 patients (100 for Gocovri and 96 for placebo). Among them, 162 patients ( 77 for Gocovri and 85 for placebo) provided evaluable diary data both at baseline and at week 12 (pooled "diary population"). Of the $34(17.3 \%)$ patients who did not meet criteria for inclusion in this diary analysis, 28 patients $(14.3 \%)$ dropped out prior to week 12 and 6 patients $(3.0 \%)$ failed to provide evaluable diaries or had incomplete diaries at baseline (Supplementary Table 1).

Baseline characteristics of the overall pooled mITT population have been reported previously [18]; baseline characteristics of the pooled diary population used for this analysis are summarized by treatment group in Table 1 and resembled the overall mITT population [18]. On average, diary population patients were 64.5 years of age (range, 34-82) and had a 9.9-year duration of PD (range, 1.0-26.8), a 7.6-year duration of levodopa treatment (range, 1.2-20.3), a 3.8-year duration of dyskinesia (range, 0.1-14.0), 5.0 hours/day of ON time with troublesome dyskinesia (range, 0.0-13.0), and 2.8 hours/day of OFF time (range, 0.0-10.0). 
Table 1

Baseline demographic and PD characteristics, by treatment group (pooled diary population)

\begin{tabular}{|c|c|c|c|}
\hline Variable & $\begin{array}{l}\text { Gocovri } \\
(n=77)\end{array}$ & $\begin{array}{l}\text { Placebo } \\
(n=85)\end{array}$ & $\begin{array}{l}\text { All Patients } \\
(N=162)\end{array}$ \\
\hline Age (y), mean [range] & $63.5[34-79]$ & $65.4[42-82]$ & $64.5[34-82]$ \\
\hline \multicolumn{4}{|l|}{ Sex, n (\%) } \\
\hline Male & $41(53.2 \%)$ & $50(58.8 \%)$ & $91(56.2 \%)$ \\
\hline Female & $36(46.8 \%)$ & $35(41.2 \%)$ & $71(43.8 \%)$ \\
\hline \multicolumn{4}{|l|}{ Race, n (\%) } \\
\hline White & $74(96.1 \%)$ & $79(92.9 \%)$ & $153(94.4 \%)$ \\
\hline Other & $3(3.9 \%)$ & $6(7.1 \%)$ & $9(5.6 \%)$ \\
\hline $\begin{array}{l}\text { Duration of PD }(\mathrm{y}) \text {, mean } \\
\text { [range] }\end{array}$ & $10.3[2.2-26.8]$ & $9.5[1.0-19.4]$ & $9.9[1.0-26.8]$ \\
\hline $\begin{array}{l}\text { Duration of levodopa } \\
\text { treatment (y), mean [range] }\end{array}$ & $8.0[1.4-20.3]$ & $7.3[1.2-18.3]$ & $7.6[1.2-20.3]$ \\
\hline $\begin{array}{l}\text { Duration of dyskinesia }(y), \\
\text { mean [range] }\end{array}$ & $4.2[0.1-14.0]$ & $3.4[0.3-11.3]$ & $3.8[0.1-14.0]$ \\
\hline $\begin{array}{l}\text { ON time with troublesome } \\
\text { dyskinesia }(\mathrm{h} / \mathrm{d}),{ }^{\mathrm{a}, \mathrm{b}} \text { mean } \\
\text { [range] }\end{array}$ & $4.8\left[0.0^{\mathrm{a}}-12.0\right]$ & $5.2[1.0-13.0]$ & $5.0\left[0.0^{\mathrm{a}}-13.0\right]$ \\
\hline $\begin{array}{l}\text { ON time without troublesome } \\
\text { dyskinesia }(\mathrm{h} / \mathrm{d}),{ }^{\mathrm{b}, \mathrm{c}} \text { mean } \\
\text { [range] }\end{array}$ & $8.5[0.0-15.0]$ & $8.1[1.0-15.0]$ & $8.3[0.0-15.0]$ \\
\hline $\begin{array}{l}\text { OFF time }(\mathrm{h} / \mathrm{d}),^{\mathrm{b}} \text { mean } \\
\text { [range] }\end{array}$ & $3.1[0.0-10.0]$ & $2.6[0.0-9.0]$ & $2.8[0.0-10.0]$ \\
\hline $\begin{array}{l}\text { MDS-UPDRS item } 4.2 \\
\text { score, }{ }^{\mathrm{d}} \text { mean [range] }\end{array}$ & $2.6[2-4]$ & $2.5[2-4]$ & $2.5[2-4]$ \\
\hline $\begin{array}{l}\text { UDysRS total score, mean } \\
\text { [range] }\end{array}$ & $41.7[10-76]$ & $39.1[8-62]$ & $40.4[8-76]$ \\
\hline \multicolumn{4}{|c|}{$\begin{array}{l}\text { a One patient with no troublesome dyskinesia was included as a protocol deviation. }{ }^{\mathrm{b}} \text { Two-day average, } \\
\text { from 24-hour PD home diaries. }{ }^{\mathrm{c}} \text { ON time without troublesome dyskinesia is the sum of ON time without } \\
\text { dyskinesia and ON time with non-troublesome dyskinesia. }{ }^{\mathrm{d}} \text { Functional impact of dyskinesias, rated from } \\
0 \text { (none) to } 4 \text { (severe). h/d, hours per day; MDS-UPDRS, Movement Disorder Society-Unified Parkinson's } \\
\text { Disease Rating Scale; mITT, modified intent-to-treat; PD, Parkinson's disease; UDysRS, Unified Dyskinesia } \\
\text { Rating Scale; y, years. }\end{array}$} \\
\hline
\end{tabular}

\section{Baseline daily pattern of PD motor complications}

In order to understand the temporal pattern of dyskinesia and OFF, measured in 30-minute intervals among patients with $\mathrm{PD}$, we determined the proportion of patients experiencing each PD state over the 17-hour waking day at baseline (Fig. 1A). At baseline, the proportion of patients experiencing troublesome dyskinesia rose from $5 \%$ to $24 \%$ over the 2 hours following morning awakening and then fluctuated between $20 \%$ and $44 \%$ through hour 15 , before decreasing as patients fell asleep. The proportion of patients in the OFF state was highest (67\%) upon morning awakening, decreased to $13 \%$ by hour 2 , and then was relatively steady at $\sim 12 \%$ (range, $6 \%-17 \%$ ) until onset of sleep. The proportions of patients experiencing ON without troublesome dyskinesia (Good ON) rose from $28 \%$ at wake-up to $63 \%$ by 2 hours, varied between $40 \%$ and $62 \%$ through hour 15 , and then decreased as patients went to sleep (Fig. 1A).
The proportions of patients in each diary state are charted across half-hour intervals, by treatment group, at baseline and week 12 in Fig. 1B. For Gocovri-treated patients, an average of $24 \%$ more patients experienced Good ON during any half-hour period, at week 12 compared with baseline. This increase was due to mean reductions in both the percentages of patients who experienced $\mathrm{ON}$ with troublesome dyskinesia (-20\%) and OFF $(-4 \%)$. In contrast, for the placebo group, an average of $8 \%$ more patients experienced Good ON during any halfhour period at week 12 compared with baseline. This was due to mean reductions in the percentages of patients reporting troublesome dyskinesia $(-11 \%)$ but not OFF $(+3 \%)$. At week 12, for 32 of the 34 measured half-hour waking intervals $(94 \%)$, a greater percentage of patients treated with Gocovri experienced Good ON compared with placebo; for 24 of these intervals $(70.6 \%)$ this prevalence difference favored Gocovri by $>10 \%$. 
A
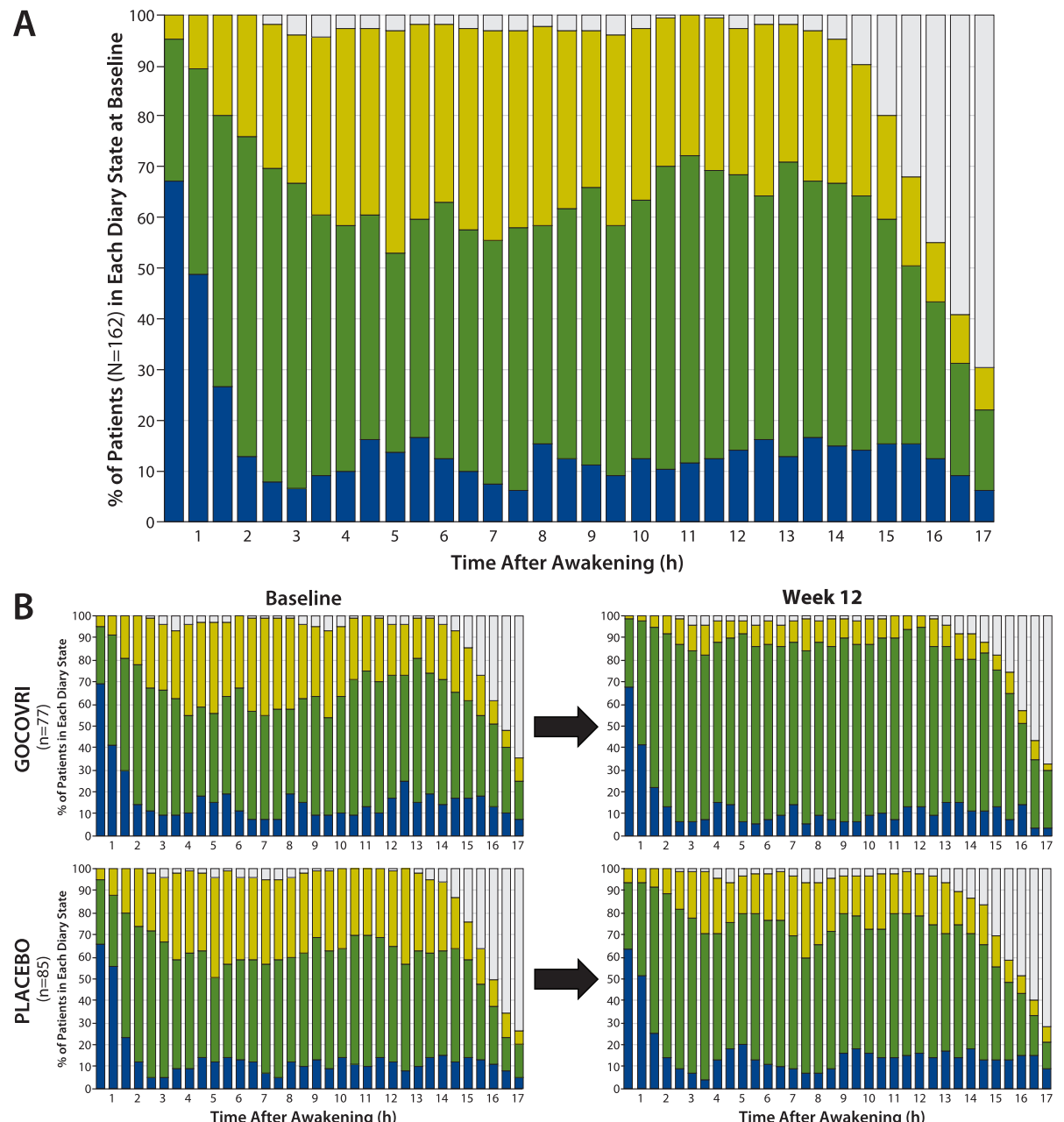

C
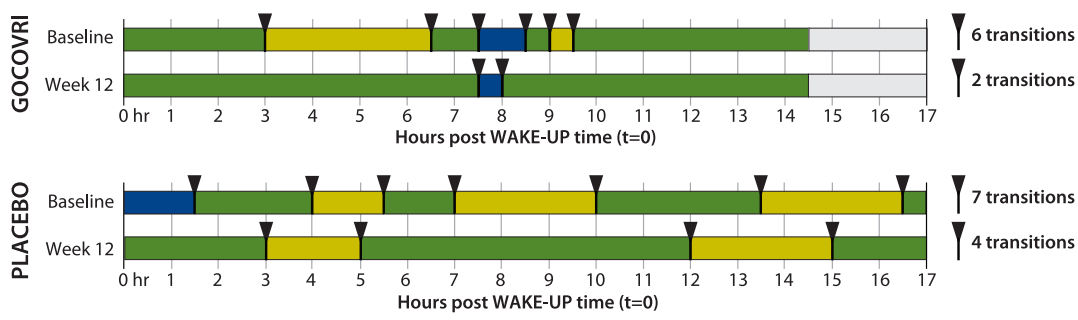

$\square$ OFF $\square$ ON with troublesome dyskinesia $\quad \square$ ON without troublesome dyskinesia $\square$ Asleep

Marks a transition between diary states

Fig. 1. Proportion of patients in each PD state during each half-hour interval of the waking day, based on PD home-diary data. A. At baseline (pooled diary population; $N=162$ ). B. By treatment group at baseline and at 12 weeks (pooled diary population; $n=77$ for Gocovri and $n=85$ for placebo). C. Example of individual patient experiences. For each treatment group, the sample patient was chosen for display who most closely represented the treatment group median values using the following hierarchy: 1) patient with median value for change in transitions; if more than one patient, then 2) select those with transition count at baseline closest to the group median; then 3) select the patient whose change in ON without troublesome dyskinesia was closest to the group median. Diary plots of episodes and transitions are shown for all patients, graphed in "heat map" fashion, in the Supplemental Material. 
Table 2

PD state episodes as derived from diary data, by treatment group (pooled diary population)

\begin{tabular}{|c|c|c|c|c|c|c|c|}
\hline \multirow[t]{2}{*}{ Variable } & \multicolumn{3}{|c|}{ Gocovri $(n=77)$} & \multicolumn{3}{|c|}{ Placebo $(n=85)$} & \multirow{2}{*}{$\frac{\text { All }(N=162)}{\text { Baseline }}$} \\
\hline & Baseline & Week 12 & Change & Baseline & Week 12 & Change & \\
\hline \multicolumn{8}{|l|}{ Transitions } \\
\hline Number of transitions, mean (SD) & $8.6(4.5)$ & $4.4(4.0)$ & $-4.2(4.5)$ & $7.6(3.5)$ & $5.6(3.5)$ & $-2.0(3.4)$ & $8.1(4.0)$ \\
\hline \multicolumn{8}{|l|}{ ON with troublesome dyskinesia } \\
\hline Number of episodes, mean (SD) & $3.0(1.6)$ & $0.9(1.4)$ & $-2.1(1.8)$ & $2.9(1.4)$ & $1.8(1.5)$ & $-1.1(1.7)$ & $3.0(1.5)$ \\
\hline Duration of an episode (h), mean (SD) & $1.9(1.8)$ & $0.7(1.2)$ & $-1.2(2.2)$ & $2.1(2.0)$ & $1.5(1.8)$ & $-0.6(2.2)$ & $2.0(1.9)$ \\
\hline Duration of first episode $^{\mathrm{a}}(\mathrm{h})$, mean (SD) & $1.9(1.9)$ & $0.8(1.3)$ & $-1.2(2.3)$ & $2.1(2.1)$ & $1.4(1.8)$ & $-0.7(2.3)$ & $2.0(2.0)$ \\
\hline \multicolumn{8}{|l|}{ OFF } \\
\hline Number of episodes, mean (SD) & $2.4(1.8)$ & $1.9(1.8)$ & $-0.5(1.6)$ & $2.0(1.7)$ & $1.8(1.5)$ & $-0.1(1.4)$ & $2.2(1.8)$ \\
\hline Duration of an episode (h), mean (SD) & $1.0(0.8)$ & $0.9(0.7)$ & $-0.2(0.8)$ & $1.1(1.0)$ & $1.3(1.0)$ & $+0.1(1.1)$ & $1.1(0.9)$ \\
\hline Duration of first episode ${ }^{\mathrm{a}}(\mathrm{h})$, mean (SD) & $1.0(0.8)$ & $0.8(0.7)$ & $-0.2(0.9)$ & $1.1(1.1)$ & $1.1(0.9)$ & $0.0(1.2)$ & $1.1(1.0)$ \\
\hline \multicolumn{8}{|l|}{ ON without troublesome dyskinesia } \\
\hline Number of episodes, mean (SD) & $4.2(2.0)$ & $2.6(1.6)$ & $-1.6(2.2)$ & $3.7(1.4)$ & $3.0(1.5)$ & $-0.8(1.7)$ & $4.0(1.8)$ \\
\hline Duration of an episode (h), mean (SD) & $2.3(1.7)$ & $7.3(5.5)$ & $+5.0(5.1)$ & $2.4(1.5)$ & $4.4(4.1)$ & $+2.0(3.7)$ & $2.4(1.6)$ \\
\hline Duration of first episode $^{\mathrm{a}}$ (hours), mean (SD) & $2.1(1.8)$ & $7.3(5.8)$ & $+5.2(5.3)$ & $2.3(1.8)$ & $4.3(4.3)$ & $+2.0(4.0)$ & $2.2(1.8)$ \\
\hline
\end{tabular}

a "Duration of first episode" describes, for all patients, the duration of the first recorded occurrence of that diary state, regardless of whether or not it was the diary state upon wake-up. h, hours; PD, Parkinson's disease; SD, standard deviation.

\section{Dyskinesia and OFF episodes - characteristics and transitions throughout the day}

During the waking day, diary-population patients experienced, on average, 8.1 transitions between clinical-state episodes (other than sleep). At baseline, an average day included 3.0 episodes of $\mathrm{ON}$ with troublesome dyskinesia, each lasting an average of 2.0 hours, and 2.2 episodes of OFF, each lasting an average of 1.1 hours. Patients also averaged 4.0 episodes of Good ON, each lasting an average of 2.4 hours. Diary plots for each patient can be found in the Supplementary Material, and similar to those in Fig. 1C, illustrate the erratic nature of these episodes as they occur throughout the day.

Characteristics of episodes of troublesome dyskinesia and OFF, and numbers of daily PD state transitions, are summarized by treatment group in Table 2. In the Gocovri group, the average duration of each episode of ON with troublesome dyskinesia decreased by 1.2 hours, compared with 0.6 hours for placebo, and the average duration of each episode of OFF decreased by 0.2 hours, compared with an increase of 0.1 hours for placebo. For both OFF and troublesome dyskinesia, the average number of episodes and the average duration of the first such episode also showed greater decreases for Gocovri than for placebo. Episodes of Good ON exhibited corresponding increases in duration. The mean duration of individual episodes of Good $\mathrm{ON}$ increased by 5.0 hours in the Gocovri group compared to 2.0 hours in the placebo group. Notably, the duration of the first episode of the day of Good ON increased by an average of 5.2 hours in the Gocovri group, compared with 2.0 hours for placebo.

On average, diary population patients receiving Gocovri experienced 4.2 (49\%) fewer transitions between episode states at week 12 than at baseline (4.4 vs 8.6 per day), compared with 2.0 (26\%) fewer transitions (5.6 vs 7.6 per day) among patients receiving placebo, representing a Gocovri over placebo treatment difference of -2.2 transitions per day $(P=0.004)$. Example diary days from Gocovri- and placebo-treated patients representing the median reductions in the number of episode transitions for their respective groups are illustrated in Fig. 1C. The proportion of patients reporting no episodes of ON with troublesome dyskinesia [all ON time is Good ON time] at week 12 was $57.1 \%$ for Gocovri, compared with $24.7 \%$ for placebo; the proportion reporting no OFF time was $27.3 \%$, compared with $20.0 \%$, respectively; and the proportion reporting neither troublesome dyskinesia nor OFF time was $19.5 \%$, compared with $3.5 \%$, respectively. Figure 2 shows, for all patients, the distribution of baseline to week 12 change values for the duration of Good ON episodes, the duration of the first such episode, and the total number of transitions between diary state episodes. For each measure, the distributions show a large leftward shift with Gocovri treatment, indicative of improvement compared with placebo.

\section{Effect of Gocovri on cumulative hours of troublesome dyskinesia and OFF per day}

In order to ensure that the subpopulation of patients providing evaluable diary data was consistent with the 

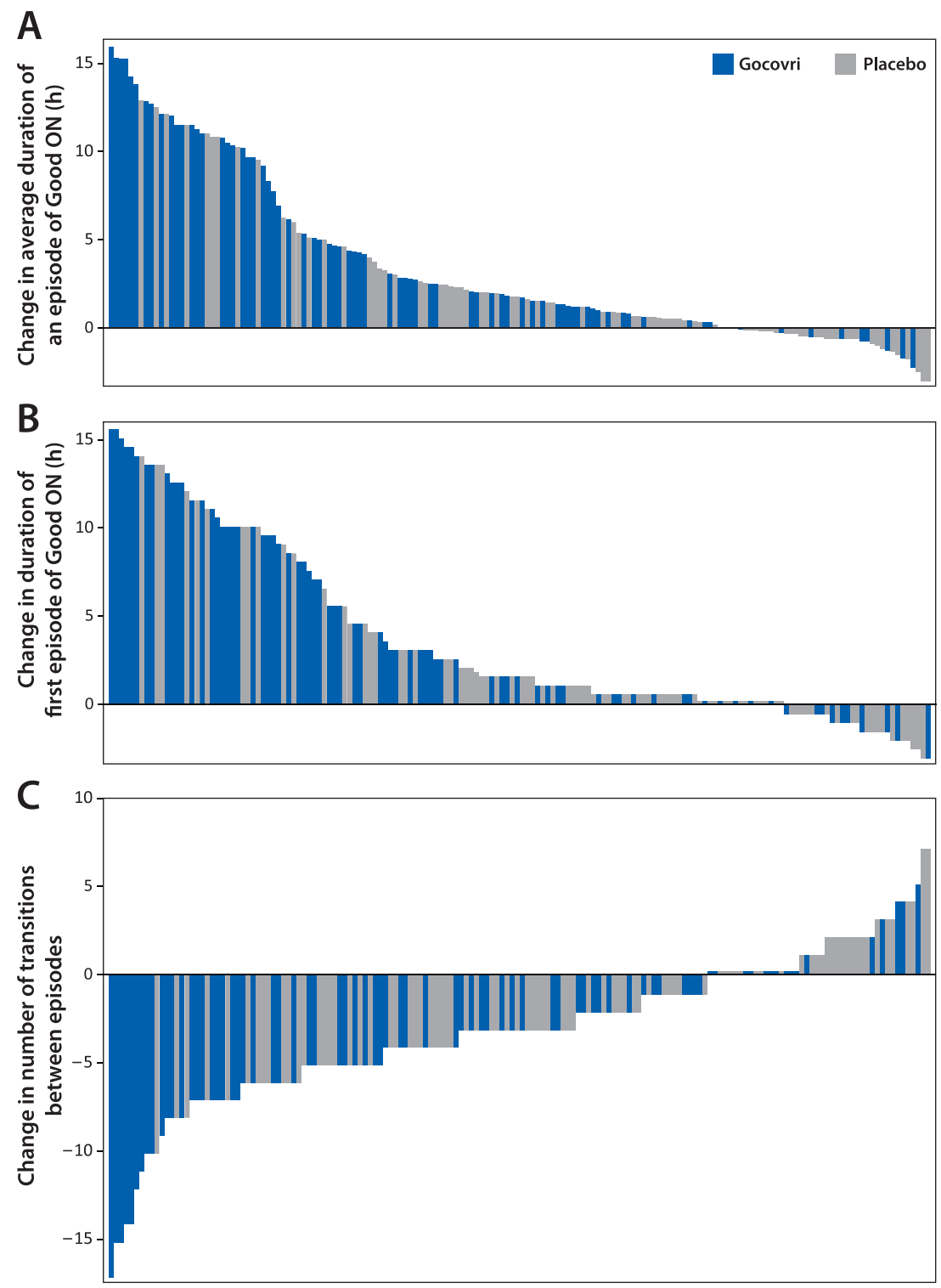

Fig. 2. Distribution of individual patient changes from baseline to week 12 in derived PD diary measures. Each bar represents an individual patient from the pooled diary population $(N=162)$; Bars show the magnitude of change at week 12. Bars showing a change of 0 have been thickened slightly. A. Each patient's mean change in duration of ON without troublesome dyskinesia (Good ON) episodes. B. Duration of first episode of Good ON. C. Number of transitions between PD diary states.

overall population from the pivotal trials, we analyzed the cumulative effect of Gocovri on PD states across the entire day. The mean changes across the entire day from baseline at week 12 for the 3 states are shown in Supplementary Table 2. The LS mean treatment difference vs placebo showed a decrease in OFF time of 1.2 hours $(95 \% \mathrm{CI}-1.73,-0.57, P<0.001)$ and a decrease in $\mathrm{ON}$ time with troublesome dyskinesia of 1.5 hours (95\% CI $-2.27,-0.67, P<0.001)$. The increase in Good ON time was 2.5 hours $(95 \%$ CI
$1.56,3.53, P<0.001)$. All values are consistent with previously reported pooled findings from EASE LID and EASE LID $3[18,19]$.

\section{Safety}

For the overall pooled population, the safety profile of Gocovri has been reported previously [18]. For the diary subpopulation, the safety profile is presented in Table 3. During the full duration of study-drug expo- 
Table 3

Adverse events during study-drug exposure ${ }^{\mathrm{a}}$ by treatment group (pooled diary population)

\begin{tabular}{|c|c|c|}
\hline Incidence, n (\%) & $\begin{array}{l}\text { Gocovri } \\
(n=77)\end{array}$ & $\begin{array}{c}\text { Placebo } \\
(n=85)\end{array}$ \\
\hline \multicolumn{3}{|l|}{ Summary } \\
\hline $\begin{array}{l}\text { Any AE leading } \\
\text { to study-drug } \\
\text { discontinuation }\end{array}$ & $3(3.9 \%)$ & $1(1.2 \%)$ \\
\hline \multicolumn{3}{|l|}{ By preferred term ${ }^{\mathrm{b}}$} \\
\hline Dizziness & $12(15.6 \%)$ & $1(1.2 \%)$ \\
\hline Constipation & $11(14.3 \%)$ & $3(3.5 \%)$ \\
\hline Hallucination $^{\mathrm{c}}$ & $11(14.3 \%)$ & $2(2.4 \%)$ \\
\hline Dry mouth & $10(13.0 \%)$ & $1(1.2 \%)$ \\
\hline Peripheral edema & $10(13.0 \%)$ & $1(1.2 \%)$ \\
\hline Fall & $9(11.7 \%)$ & $7(8.2 \%)$ \\
\hline $\begin{array}{l}\text { Urinary tract } \\
\text { infection }\end{array}$ & $8(10.4 \%)$ & $4(4.7 \%)$ \\
\hline
\end{tabular}

${ }^{a}$ Up to 25 weeks in EASE LID, and up to 13 weeks in EASE LID 3. ${ }^{\mathrm{b}}$ The list includes all preferred terms with an incidence $\geq 10.0 \%$ among patients receiving Gocovri. ${ }^{\mathrm{c}}$ Includes visual and auditory hallucination. AE, adverse event.

sure (up to 25 weeks in EASE LID and up to 13 weeks in EASE LID 3), the adverse events (AEs) reported in $\geq 10.0 \%$ of diary-population patients receiving Gocovri were dizziness, constipation, hallucination (visual or auditory), dry mouth, peripheral edema, fall, and urinary tract infection. Overall, AE frequencies in the diary subpopulation resembled those in the full pooled population [18]. However, because the subpopulation excludes patients who lacked week 12 data, it is enriched for tolerability and showed a lower proportion of patients with AEs leading to discontinuation relative to the full pooled population, at $3.9 \%$ vs $20.0 \%$ [18].

\section{DISCUSSION}

Analyses of diary data in clinical trials of medications for PD patients with motor fluctuations and/or dyskinesia have typically focused on measures of total daily OFF time, total daily ON time without troublesome dyskinesia, and total daily $\mathrm{ON}$ time with troublesome dyskinesia. Here we provide a more in-depth analysis of diary data and present novel approaches that, to our knowledge, have not been reported for adjunctive medications previously. We first evaluated the population-level pattern of troublesome dyskinesia and OFF prevalence through the day, assessed by half-hour intervals. We then evaluated the effect of Gocovri on troublesome dyskinesia and OFF through the day using the same novel analytical method. We wanted to know whether, for example, troublesome dyskinesia (on a population basis) tends to build through the day and is more prevalent in the late afternoon and evening compared to the morning or whether troublesome dyskinesia was essentially evenly distributed throughout the day. Our results indicate that, at the study population level, troublesome dyskinesia increased in the first hours following wake-up and was then prevalent throughout the day $(20 \%-44 \%)$, whereas there was a peak of OFF early in the morning, followed by a lower $(6-17 \%)$ distribution throughout the rest of the waking day. We also wanted to discern whether Gocovri exerted its benefit during a specific part of the day, or whether it provided benefit throughout the day. Results suggest that it provided benefit throughout the day, consistent with its pharmacokinetic profile [12].

In a second set of analyses, we evaluated individual episodes of troublesome dyskinesia, OFF, and Good ON (ON without troublesome dyskinesia), which could extend through multiple 30-minute intervals. We evaluated the mean number of these daily episodes and their mean duration, both at baseline and following treatment with Gocovri or placebo. To our knowledge, this is the first time such an analysis has been performed for an adjunctive medication in PD. We also evaluated the number of transitions between diary states at baseline and following treatment. Results indicated that Gocovri reduced both the number and duration of individual episodes of troublesome dyskinesia and OFF through the day, as well as the number of daily transitions between PD motor states.

While studies have clearly identified an inverse relationship between QOL and daily amount of OFF time and troublesome dyskinesia $[4,19]$, there is little information available about the relationship between number of transitions between PD states and QOL. It seems likely that longer duration of episodes of $\mathrm{ON}$ without troublesome dyskinesia, coupled with fewer transitions, would lead to a better, more predictable day and would allow for better activity planning and engagement, although this remains to be rigorously studied.

An important limitation of the present work is that it is comprised of post-hoc analyses of pre-existing databases. In addition, diary data were derived from patients reporting at least mild dyskinesia at baseline (per MDS-UPDRS item 4.2) and at least one hour/day of troublesome dyskinesia (per PD home diary) between the hours of 9 am and $4 \mathrm{pm}$. Thus, the analyses may not reflect a more generalized PD population not selected for timing, type, or severity of 
dyskinesia or OFF episodes. However, patients with evening dyskinesia were not excluded, provided they also had dyskinesia between 9 am and $4 \mathrm{pm}$. In fact, the percentages of patients reporting dyskinesia late in the day (but before sleep) were similar to the percentages reporting dyskinesia earlier in the day (see Fig. 1). Another limitation is that the study's measures of clinical states did not include tools for capturing the intensity of each state (except for categorizing the presence of dyskinesia as troublesome or not). In the future, wearable sensors and other types of monitors may provide continuous monitoring through the day and allow more sensitive assessment of mild motor fluctuations and dyskinesia. Lastly, our analyses only included the $83 \%$ of enrolled patients who provided evaluable diaries at baseline and week 12 (the "diary population"). They do not include those who withdrew prematurely, or who provided non-evaluable diaries at baseline or week 12. Nonetheless, baseline demographics and diary state efficacy outcomes were found to be similar between the diary subpopulation and overall pooled population.

These analyses expand the knowledge of temporal patterns of clinical states in PD. The overall pattern of dyskinesia that we identified was a relatively steady population prevalence, from hours 2 through 15 , without clear peaks or troughs. There was a peak of OFF prevalence seen in the first hour after waking, and subsequently, a relatively steady lower prevalence from hours 2 through 15, without clear peaks or troughs. Our results also demonstrated a treatment effect of Gocovri for dyskinesia and OFF throughout the waking day.

These novel analyses of diary data can be applied to other therapies and provide additional insights regarding the patient experience through the day. We anticipate there will be increasing interest in these types of analyses as wearable sensors and other objective PD monitoring devices are introduced that can provide data that are continuously obtained through the day. Evaluating the pattern of an individual patient's clinical states and seeking therapies whose pharmacokinetics and clinical effects best match the individual's needs for amelioration of dyskinesia and OFF through the day can be a facet of personalized medicine that may lead to better clinical management and improved patient satisfaction.

\section{ACKNOWLEDGMENTS}

The study was funded by Adamas Pharmaceuticals. We acknowledge and thank the study participants and the EASE LID and EASE LID 3 study investigators and their staff. Editorial support was provided by Dustin Chernick and Andrea Formella, who are employees of, and own stock in Adamas Pharmaceuticals, Inc., and by The Curry Rockefeller Group, LLC, which was funded by Adamas Pharmaceuticals, Inc.

\section{CONFLICT OF INTEREST}

Robert A. Hauser is supported in part by a Center of Excellence grant from the Parkinson Foundation and is employed by the University of South Florida (Florida). He received payment from Adamas Pharmaceuticals for participating as a Steering Committee member and reports receiving fees from Adamas Pharmaceuticals, Teva Pharmaceuticals, UCB BioSciences, AbbVie, Novartis, Biotie Therapies, Lundbeck, Pfizer, Allergan Neuroscience, Neurocrine Biosciences, Chelsea Therapeutics, Auspex Pharmaceuticals, Acadia Pharmaceuticals, Michael J. Fox Foundation, GLG, AstraZeneca, Acorda Therapeutics, Impax Pharmaceuticals, Cynapsus Therapeutics, US WorldMeds, Neuropore, and Prexton Therapeutics.

Daniel E. Kremens has been a consultant and speaker bureau member for Acadia, Adamas, Impax, Lundbeck, Teva, UCB, and US WorldMeds; a consultant for AbbVie, Allergan, GE Healthcare, Kyowa, Merz, Neurocrine, St. Jude Medical, and Sunovion; a researcher for Enterin and Revance; and a researcher and consultant for Acorda.

Lawrence W. Elmer has received honoraria for speaking engagements from Lundbeck, Novartis, UCB Pharma, and Teva Neuroscience; has served as a paid consultant for Teva Neuroscience and UCB Pharma; has received honoraria as a member of advisory boards for Lundbeck, Teva Neuroscience, and UCB Pharma; and has received unrestricted educational grant support from Teva Neuroscience.

David L. Kreitzman has been a principal investigator (PI) for several IPX066 trials and has served on one Impax Laboratories, Inc., advisory board, for which he received compensation from the sponsor for these activities. He currently is a PI, and has been so over the past 5 years, for several clinical trials sponsored by Adamas Pharmaceuticals, Teva Pharmaceuticals, Pharma Two B Ltd., Impax Laboratories, Inc., Neuraltus Pharmaceuticals, Inc., Chelsea Therapeutics, US WorldMeds, LLC., Ipsen Biopharmaceuticals, and Acadia Pharmaceuticals Inc. In 
addition, he currently is a speaker and consultant, and has been so over the past 5 years, for several pharmaceutical companies, including Teva Pharmaceuticals, Impax, US WorldMeds, LLC., XenoPort, Boehringer Ingelheim, Novartis, and UCB.

Ryan R. Walsh has received consulting compensation from Lundbeck, Acadia, Teva, AbbVie, and Wilson Therapeutics, and research funding support from Parkinson's Disease Foundation Postdoctoral Fellowship in Clinical Research, Civitan International Research Center Emerging Scholars Award, NIH-NIGMS Center of Biomedical Research Excellence P20GM109025, Project PI (Center PI: Jeff Cummings), Elaine P. Wynn \& Family Foundation Lee Pascal Parkinson's Disease Scholar, Sam and Peggy Grossman Foundation, and Samuel P. Mandell Foundation.

Robert Howard is a paid statistical consultant for Adamas Pharmaceuticals.

Reed Johnson, Jack T. Nguyen, and Rajiv Patni are employees of, and own stock in Adamas Pharmaceuticals.

\section{SUPPLEMENTARY MATERIAL}

The supplementary material is available in the electronic version of this article: http://dx.doi.org/ 10.3233/JPD-181565.

\section{REFERENCES}

[1] Schapira AH, Emre M, Jenner P, Poewe W (2009) Levodopa in the treatment of Parkinson's disease. Eur J Neurol, 16, 982-989.

[2] Chapuis S, Ouchchane L, Metz O, Gerbaud L, Durif F (2005) Impact of the motor complications of Parkinson's disease on the quality of life. Mov Disord, 20, 224-230.

[3] LeWitt PA, Fahn S (2016) Levodopa therapy for Parkinson disease: A look backward and forward. Neurology, 86, S312.

[4] Damiano AM, McGrath MM, Willian MK, Snyder CF, LeWitt PA, Reyes PF, Richter RR, Means ED (2000) Evaluation of a measurement strategy for Parkinson's disease: Assessing patient health-related quality of life. Qual Life Res, 9, 87-100.

[5] Khlebtovsky A, Rigbi A, Melamed E, Ziv I, Steiner I, Gad A, Djaldetti R (2012) Patient and caregiver perceptions of the social impact of advanced Parkinson's disease and dyskinesias. J Neural Transm (Vienna), 119, 1367-1371.

[6] Ahlskog JE, Muenter MD (2001) Frequency of levodoparelated dyskinesias and motor fluctuations as estimated from the cumulative literature. Mov Disord, 16, 448-458.

[7] Muller T, Woitalla D, Russ H, Hock K, Haeger DA (2007) Prevalence and treatment strategies of dyskinesia in patients with Parkinson's disease. J Neural Transm (Vienna), 114, 1023-1026.
[8] Schaeffer E, Pilotto A, Berg D (2014) Pharmacological strategies for the management of levodopa-induced dyskinesia in patients with Parkinson's disease. CNS Drugs, 28, 1155-1184.

[9] Videnovic A, Willis GL (2016) Circadian system - a novel diagnostic and therapeutic target in Parkinson's disease? Mov Disord, 31, 260-269.

[10] Chase TN, Oh JD (2000) Striatal mechanisms and pathogenesis of parkinsonian signs and motor complications. Ann Neurol, 47, S122-129; discussion S129-130.

[11] Danysz W, Parsons CG, Kornhuber J, Schmidt WJ, Quack G (1997) Aminoadamantanes as NMDA receptor antagonists and antiparkinsonian agents-preclinical studies. Neurosci Biobehav Rev, 21, 455-468.

[12] Hauser RA, Pahwa R, Wargin WA, Souza-Prien CJ, McClure N, Johnson R, Nguyen JT, Patni R, Went GT (2019) Pharmacokinetics of ADS-5102 (amantadine) extended release capsules administered once daily at bedtime for the treatment of dyskinesia. Clin Pharmacokinet, 58, 77-88.

[13] Pahwa R, Tanner CM, Hauser RA, Isaacson SH, Nausieda PA, Truong DD, Agarwal P, Hull KL, Lyons KE, Johnson R, Stempien MJ (2017) ADS-5102 (Amantadine) extended-release capsules for levodopa-induced dyskinesia in Parkinson disease (EASE LID study): A randomized clinical trial. JAMA Neurol, 74, 941-949.

[14] Oertel W, Eggert K, Pahwa R, Tanner CM, Hauser RA, Trenkwalder C, Ehret R, Azulay JP, Isaacson S, Felt L, Stempien MJ (2017) Randomized, placebo-controlled trial of ADS-5102 (amantadine) extended-release capsules for levodopa-induced dyskinesia in Parkinson's disease (EASE LID 3). Mov Disord, 32, 1701-1709.

[15] Hauser RA, Friedlander J, Zesiewicz TA, Adler CH, Seeberger LC, O’Brien CF, Molho ES, Factor SA (2000) A home diary to assess functional status in patients with Parkinson's disease with motor fluctuations and dyskinesia. Clin Neuropharmacol, 23, 75-81.

[16] International Parkinson and Movement Disorder Society (MDS), Unified Dyskinesia Rating Scale (UDysRS), http://www.movementdisorders.org/MDS-Files1/PDFs/ UDysRS_English_FINAL.pdf, Accessed 12 February 2019.

[17] Goetz CG, Tilley BC, Shaftman SR, Stebbins GT, Fahn S, Martinez-Martin P, Poewe W, Sampaio C, Stern MB, Dodel R, Dubois B, Holloway R, Jankovic J, Kulisevsky J, Lang AE, Lees A, Leurgans S, LeWitt PA, Nyenhuis D, Olanow CW, Rascol O, Schrag A, Teresi JA, van Hilten JJ, LaPelle N, Movement Disorder Society UPDRS Revision Task Force (2008) Movement Disorder Society-sponsored revision of the Unified Parkinson's Disease Rating Scale (MDS-UPDRS): Scale presentation and clinimetric testing results. Mov Disord, 23, 2129-2170.

[18] Elmer LW, Juncos JL, Singer C, Truong DD, Criswell SR, Parashos S, Felt L, Johnson R, Patni R (2018) Pooled analyses of Phase III studies of ADS-5102 (Amantadine) extended-release capsules for dyskinesia in Parkinson's disease. CNS Drugs, 32, 387-398.

[19] Hechtner MC, Vogt T, Zollner Y, Schroder S, Sauer JB, Binder H, Singer S, Mikolajczyk R (2014) Quality of life in Parkinson's disease patients with motor fluctuations and dyskinesias in five European countries. Parkinsonism Relat Disord, 20, 969-974. 